\title{
DIFFUSING CAPACITY LIMITATIONS OF THE EXTENT OF LUNG VOLUME REDUCTION SURGERY IN AN ANIMAL MODEL OF EMPHYSEMA
}

John C. Chen, MD

Dan L. Serna, MD

Matt Brenner, MD

Ledford L. Powell, MD

Joseph Huh, MD

Robert McKenna, Jr, MD

Richard J. Fischel, MD, PhD

Arthur Gelb, MD

Jill Monti, BS

Tanya Burney

Mark D. Gaon, BS

Henry Aryan, BS

Archie Wilson, MD, PhD
Objective: The purpose of this study was to investigate in an elastaseinduced emphysema rabbit model the effects of increasing resection volumes during lung volume reduction surgery on pulmonary compliance, forced expiratory air flow, and diffusing capacity to assess factors limiting optimal resection. Methods: Emphysema was induced in $68 \mathrm{New}$ Zealand White rabbits with $\mathbf{1 5 , 0 0 0}$ units of aerosolized elastase. Static respiratory system compliance, forced expiratory flow, and singlebreath diffusing capacity were measured before the induction of emphysema, after the induction of emphysema, and 1 week after a bilateral upper and middle lobe lung volume reduction operation. Results: Static respiratory system compliance with $60 \mathrm{~mL}$ insufflation above functional residual capacity increased with emphysema induction and then decreased progressively with resection of larger volumes of lung tissue $(P=.001$ by analysis of variance). Expiratory flow improved after lung resection in the rabbits with large resection volumes. In contrast, diffusing capacity tended to deteriorate with larger resection volumes $(P=$ .18). Conclusion: Improvements in respiratory system compliance and forced expiratory flow after lung volume reduction operations may account for the improvements seen clinically. Declines in diffusing capacity with extensive lung reduction may limit the clinical benefits associated with greater tissue resection volumes. Future investigations with animal models may reveal other physiologic parameters that may further guide optimal lung volume reduction procedures. (J Thorac Cardiovasc Surg 1999;117:728-35)
$\mathrm{E}_{\mathrm{pr}}^{\mathrm{m}}$ mphysema is a devastating disease characterized by progressive alveolar deterioration and disordered pulmonary physiology. Recently interest has developed with respect to lung volume reduction surgery as a potential treatment for emphysema.

From the University of California Irvine Medical Center, Orange, Calif, Divisions of Cardiothoracic Surgery, Pulmonary and Critical Care Medicine, and Beckman Laser Institute, Irvine, Calif.

Supported by DOE grant DE-FG03-91ER61, ALA grant CI-030-17, CTRDRP grant 6RT0158, Chapman Medical Center Research Grant, and American College of Surgeons Faculty Research Grant.

Read at the Seventy-eighth Annual Meeting of The American Association for Thoracic Surgery, Boston, Mass, May 3-6, 1998.

Received for publication May 8, 1998; revisions requested July 14, 1998; revisions received Oct 23, 1998; accepted for publication Dec 9, 1998.

Address for reprints: Matthew Brenner, MD, Pulmonary and Critical Care Medicine Division, University of California Irvine Medical Center, 101 The City Dr, Building 53, Room 119, Orange, CA 92868-3298.

Copyright $(9) 1999$ by Mosby, Inc.

$0022-5223 / 99 \$ 8.00+0 \quad \mathbf{1 2 / 6 / 9 6 4 0 3}$
Emphysema causes pulmonary hyperinflation, airway obstruction, and increased pulmonary compliance. Experimental evidence has demonstrated a reduction in total lung volume after lung volume reduction surgery, which may restore the mechanics of breathing to a more physiologically usual state. ${ }^{1}$ Previous clinical and laboratory investigation found improvements in air flow and pulmonary compliance to occur with lung volume reduction surgery. ${ }^{1-4}$ Although it is speculated that greater physiologic benefit might be gained with higher resection volumes, some physiologic parameters must limit the extent of tolerable resection. Diffusing capacity has been shown to decrease with extensive pulmonary tissue resection in an animal model of lung volume reduction surgery. ${ }^{5}$ Changes in diffusing capacity occurring with lung volume reduction surgery have not been correlated with changes in air flow and pulmonary compliance as resection volumes increase. A clear understanding of both the physiologic benefits and the diminishing returns associated with increasing resection volumes would facilitate optimal clinical outcome 
with lung volume reduction surgery. The purpose of this study was to investigate the effects of progressively increasing lung resection volumes on pulmonary compliance, air flow, and diffusing capacity in an animal model of elastase-induced emphysema.

\section{Methods}

The Institutional Animal Care and Use Committee at the University of California, Irvine, approved this protocol. All rabbits were cared for in accordance with the "Guide for the Care and Use of Laboratory Animals" prepared by the Institute of Laboratory Animal Resources and published by the National Institutes of Health (NIH Publication No. 86-23, revised 1985).

Animal preparation. Sixty-eight adult male New Zealand White rabbits (2.3-4.8 kg) were anesthetized intramuscularly with a 2:1 mixture of ketamine hydrochloride $(100 \mathrm{mg} / \mathrm{mL})$ and xylazine $(20 \mathrm{mg} / \mathrm{mL})$ at a dose of $0.75 \mathrm{~mL} / \mathrm{kg}$. The rabbits were intubated with a 3-mm endotracheal tube and received mechanical ventilation (Harvard Apparatus Dual Phase Control Respiratory Pump-Canine, Harvard Co, South Natick, Mass) with a tidal volume of $50 \mathrm{~mL}$ and a respiratory rate of 30 to $40 \mathrm{breaths} / \mathrm{min}$. One 20 -gauge intravenous catheter was placed in a marginal ear vein for vascular access. Anesthesia was maintained with $0.3 \mathrm{~mL}$ of a $1: 1$ mixture of ketamine hydrochloride $(100 \mathrm{mg} / \mathrm{mL})$ and xylazine $(20$ $\mathrm{mg} / \mathrm{mL}$ ) given as an intravenous bolus as needed to maintain apnea throughout all procedures.

Induction of emphysema. Emphysema was induced in 68 rabbits that were under general anesthesia by aerosolizing 15,000 units $(7.89 \mathrm{~mL})$ of porcine elastase (Worthington Biochemical Corporation, Lakewood, NJ) through the endotracheal tube during approximately 1 hour. The nebulizer (Respirgard; Marquest Medical Products, Inc, Englewood, Colo) was connected to the inspiratory arm of the ventilator circuit with the ventilator set to a tidal volume of zero and a respiratory rate of $30 \mathrm{breaths} / \mathrm{min}$. The oxygen flow through the nebulizer was adjusted to maintain a peak airway pressure of $20 \mathrm{~cm} \mathrm{H}_{2} \mathrm{O}$. An analog manometer placed at the side port of the endotracheal tube monitored the peak airway pressure.

Pulmonary function testing. Lung function measurements were obtained at baseline before induction of emphysema, immediately before the operation at 4 weeks after induction of emphysema, and 1 week after the operation. Static respiratory system compliance, forced expiratory flow, and diffusing capacity were measured at each interval.

Static respiratory system compliance measurement. To measure static respiratory system pressures the anesthetized, apneic rabbits were disconnected from the ventilator and placed in the left decubital position. A $60-\mathrm{mL}$ syringe was attached to the end of the endotracheal tubes and the lungs were inflated to a volume $60 \mathrm{~mL}$ above functional residual capacity (FRC) 3 times to establish a constant volume history. The lungs were allowed to passively deflate. Static respiratory system pressures were measured separately at each inflation volume of $60,50,40,30$, and $20 \mathrm{~mL}$ above FRC.
The appropriate volume was injected and the syringe was held in place for 5 seconds while static airway pressure was measured. The syringe was then released and the lungs were allowed to passively deflate. Static respiratory system pressures were measured with a water manometer (10AA25; Meriam Instruments, Cleveland, Ohio) connected to the side port of the endotracheal tube. The rabbits were returned to mechanical ventilation after the measurements. Compliance was calculated by dividing the sum of the FRC and inflation volume above FRC by the measured static respiratory system pressure at each inflation volume.

Dynamic expiratory flow measurement. The anesthetized rabbits were placed into a sealed acrylic box for measurement of forced expiratory flows. The endotracheal tube was connected to an external port through which the rabbits were ventilated while in the box. A pneumotachometer and flow transducer (MP45-14; Validyne Engineering Corp, Northridge, Calif) was connected to the external port for air flow measurements. The box was pressurized and maintained at $20 \mathrm{~cm} \mathrm{H} \mathrm{H}_{2} \mathrm{O}$ pressure to simulate a forced expiratory maneuver by the rabbits.

Volumes of $60 \mathrm{~mL}$ greater than FRC were injected in the airway through the pneumotachometer with a syringe. The syringe was disconnected from the pneumotachometer and the rabbit was allowed to exhale the $60 \mathrm{~mL}$ through the pneumotachometer. This expiratory maneuver was repeated 4 times and results were averaged for each rabbit. To verify that maximal flows were achieved at $20 \mathrm{~cm} \mathrm{H}_{2} \mathrm{O}$ the forced expiratory maneuver was repeated at a higher pressure of $25 \mathrm{~cm} \mathrm{H}_{2} \mathrm{O}$ to demonstrate approximate equivalence of maximal flows.

The flow transducer was calibrated with a $60-\mathrm{mL}$ syringe immediately before each expiratory measurement. An analog-to-digital converter (Keithley System 570; Keithley, Cleveland, Ohio) sampling at $60 \mathrm{~Hz}$ was used to digitize the pressure transducer data, which were then stored on an IBM personal computer (IBM Corp, White Plains, NY). Flow was converted to volume by integration across time. Forced expiratory flows at $60 \mathrm{~mL}$ inflation were calculated from the digital data.

Single-breath carbon monoxide diffusing capacity. The inhalation gasses consisted of $9.30 \%$ helium, $60.50 \%$ oxygen, $29.05 \%$ nitrogen, $0.87 \%$ ethylene, and $0.28 \%$ carbon monoxide labeled with oxygen 18 (Liquid Carbonics Corp, Los Angeles, Calif). All gas concentrations were measured continuously with an on-line mass spectrometer (MGA 1100; Perkins-Elmer Corp, Pomona, Calif). Analog data were converted to digital information with an analog-to-digital converter (Keithley System 570) sampling at $20 \mathrm{~Hz}$ and stored on an IBM personal computer.

The anesthetized and intubated rabbits were removed from the ventilator and placed in a left decubital position. The sampling tube of the mass spectrometer was connected to the side port of the endotracheal tube through which the inspired and expired gas concentrations were continuously measured. A syringe was filled to $60 \mathrm{~mL}$ with inhalation gases and connected to the endotracheal tube.

Five-second breath-holding carbon monoxide diffusing 


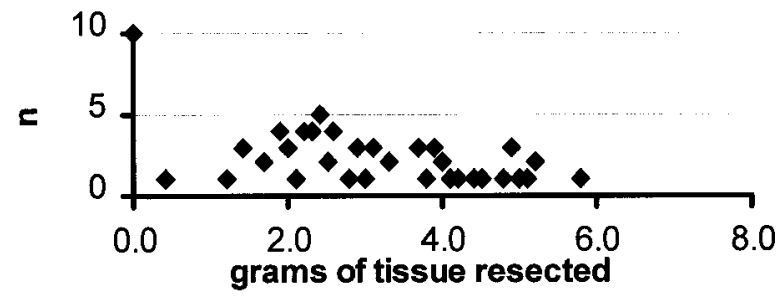

Fig 1. Graph shows distribution of lung tissue resected.

capacity (DLCO) maneuvers were performed on each rabbit. All gas concentrations were measured continuously through the mass spectrometer. A $60-\mathrm{mL}$ portion of the inhalation gas was insufflated into the lung through the endotracheal tube and held for 5 seconds. A 30-mL portion of the inspired volume was then withdrawn and held to measure the gas concentrations at $50 \%$ of expired volume. All data were sampled and digitized at $20 \mathrm{~Hz}$.

For analysis the breath-holding time was measured from 0.5 seconds from the start of inspiration to $30 \mathrm{~mL}$ exhalation. The duration of inhalation was rapid, and peak concentrations were achieved within 1 second. The initial concentration of carbon monoxide labeled with oxygen 18 was measured at its plateau after gas insufflation. The final gas concentration was measured at $30 \mathrm{~mL}$ exhalation. DLCO was calculated from the standard formula and corrected to standard temperature and pressure dry conditions. DLCO was expressed in terms of milliliters of carbon monoxide that would diffuse for each difference of $1 \mathrm{~mm} \mathrm{Hg}$ between alveolar partial pressure of carbon monoxide and pulmonary blood carbon monoxide pressure.

Lung volume reduction surgery. Lung volume reduction surgery was performed 4 weeks after elastase induction of emphysema. The anterior chest wall of the anesthetized and intubated rabbit was shaved and the rabbit was placed in a supine position. Fifty-eight rabbits underwent resection of varying quantities of lung tissue. Ten control rabbits underwent median sternotomy and chest tube placement with no excision of lung tissue (sham operation).

Hypothermia was prevented with a surgical warming pad. Ringer's lactate solution was infused through an intravenous catheter in a marginal ear vein at a rate of 5 to $15 \mathrm{~mL} / \mathrm{h}$. The rabbits received mechanical ventilation with the ventilator described previously. Oxygen saturation (Ohmeda Biox 3700 Pulse Oximeter; BOC Health Care, Boulder, Colo), tidal carbon dioxide (Ohmeda $5200 \mathrm{CO}_{2}$ Monitor; BOC Health Care), and electrocardiogram (Hewlett-Packard 78353B Continuous EKG Monitor; BioMedical Services, Andover, Mass) were monitored continuously.

The shaved chest was prepared with povidone-iodine (Betadine) and draped in sterile fashion. The thorax was entered through a median sternotomy. Bilateral upper and middle lobes were excised with a linear thoracoscopic stapler (Endopath ELC; Ethicon Endo-Surgery, Somerville, NJ) with 3.5-mm staples. Target quantity of lung tissue removed ranged from 0 to $5.8 \mathrm{~g}$. Excised lung tissue was weighed dur- ing the procedure to ensure the achievement of target resection amounts (Fig 1). During sham operations no lung tissue was excised. Hemostasis was obtained and a $12 \mathrm{~F}$ neonatal chest tube was placed into each pleural space under direct visualization. The 2 chest tubes were connected to $10 \mathrm{~cm}$ $\mathrm{H}_{2} \mathrm{O}$ suction. The sternum was closed with interrupted 0 silk suture and the chest wound was closed in layers with absorbable monofilament sutures. The rabbits were awakened from anesthesia and extubated. Any air leaks present were mild and spontaneously sealed within the first hour after the operation. All chest tubes were removed within 1 hour after the operation.

Histologic preparation. Animals were killed 1 week after the lung volume reduction operation. The lungs were removed en bloc and inflated with formalin $\left(20 \mathrm{~cm} \mathrm{H}_{2} \mathrm{O}\right.$ pressure $)$ for histologic preparation. Each rabbit lung was sectioned into upper, middle, and lower lung fields. The lung sections were prepared at 0.2 to $0.4 \mathrm{~cm}$ thicknesses and embedded in paraffin. Slides were stained with hematoxylin-eosin and studied by light microscopy. The histologic appearance was graded according to the number of alveolar walls counted from an end-terminal bronchiole toward the lung periphery. The number of walls per millimeter was noted. With this model we previously reported a statistically significant difference in the number of alveolar walls counted per millimeter between rabbits treated once with 15,000 units of elastase and control rabbits to whom no elastase was administered. ${ }^{1}$

Statistical analysis. All compliance, expiratory flow, and DLCO data for each rabbit were tabulated corresponding to baseline, preoperative, and postoperative measurements. For forced expiratory flows and diffusing capacity, comparisons of the change from the preoperative to the postoperative measurements between the 3 groups were made with analysis of variance (Systat 7.0.1; SPSS Inc, Chicago, Ill). For compliance, comparisons of postoperative values between groups were made with analysis of variance. Pressure-volume curves were generated for each treatment group from baseline, preoperative, and postoperative measurements, and a best-fit curve was generated from a polynomial equation.

\section{Results}

The mortality rate after emphysema induction was approximately $20 \%$. Deaths were caused by pneumothorax or pulmonary hemorrhage. Most of these deaths occurred within the first 24 hours after elastase administration. The surgical mortality rate was quite low compared with the mortality rate obtained after the induction of emphysema. One animal died with surgery after the resection of $4.4 \mathrm{~g}$ of lung tissue, placing it among those with the largest resection amounts. Occasionally the animals had small air leaks after the operation. Air leaks usually abated within 1 hour after the end of the operation, at which time chest tubes were removed. The 1 surgical death was of an animal with an undetected air leak, which caused death the first night after the operation. 


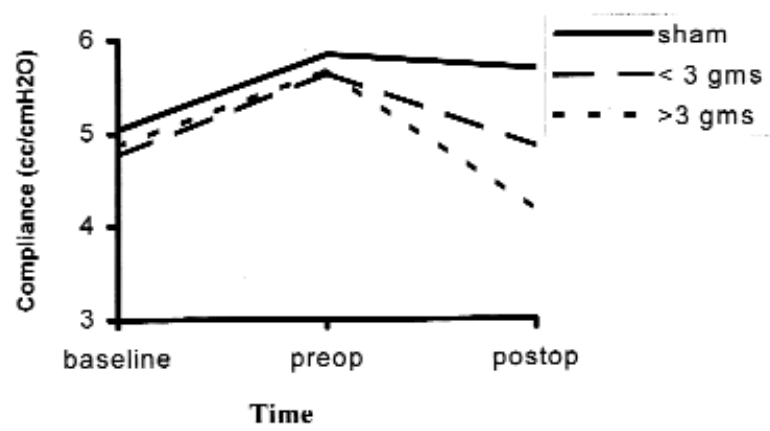

Fig 2. Graph shows change in static respiratory system compliance before induction of emphysema (baseline), immediately before lung volume reduction surgery (preop), and 1 week after lung volume reduction surgery at time animals were killed (postop). Ordinate represents static respiratory system compliance at $60 \mathrm{~mL}$ inflation above mean FRC. Compliance is expressed in milliliters per centimeter of water. Abscissa shows 3 time points at which measurements were taken. Postoperative analysis of variance, $P=.000$. Total animals tested, $\mathrm{N}=68$.

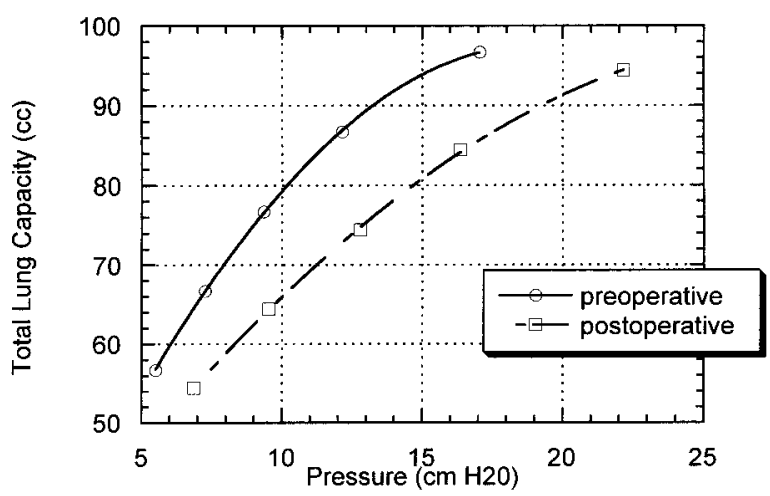

Fig 3. Graph shows pressure-volume relationship of largevolume treatment group before and after operation. Total lung capacity is expressed in milliliters and equals insufflation volume above mean FRC. Pressure is given as mean static respiratory system pressure measurements in units of centimeters of water. Total animals tested, $\mathrm{N}=68$.

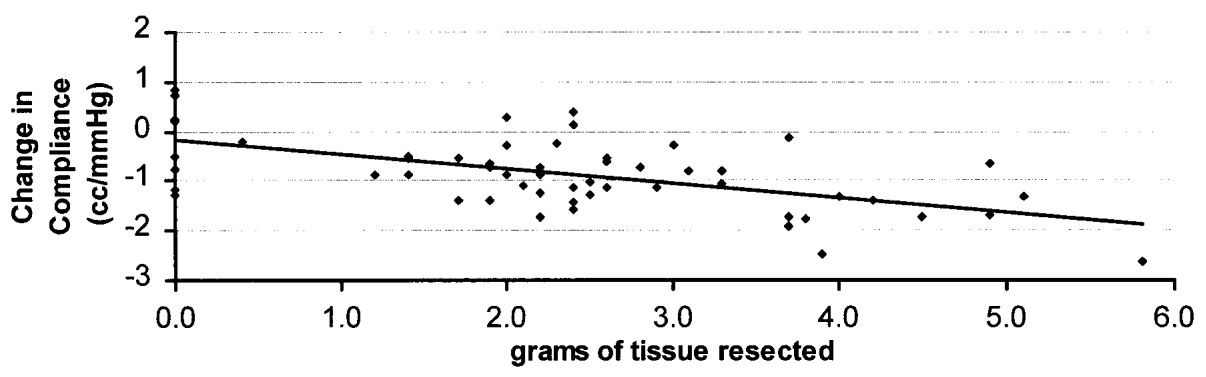

Fig 4. Graph shows change in compliance as continuous function of amount of tissue resected with lung volume reduction surgery; $r=0.590, P<.00001$. Total animals tested, $\mathrm{N}=68$.

For this analysis animals were divided into 3 treatment groups according to the amount of lung tissue excised. Group 1 underwent median sternotomy with no lung tissue resected (sham operation, group 1). Group 2 had $3 \mathrm{~g}$ or less of lung tissue resected. Group 3 had more than $3 \mathrm{~g}$ of lung tissue resected.

Compliance. Total lung capacity was calculated at each insufflation volume above FRC (gas dilution). Static respiratory system compliance was then calculated from the mean static respiratory system pressures at $60,50,40,30$, and $20 \mathrm{~mL}$ above FRC. With the induction of emphysema, static respiratory system compliance increased in all 3 treatment groups (Fig 2). The mean compliances ( \pm SEM) at $60 \mathrm{~mL}$ above FRC for groups 1, 2, and 3 were, respectively, $5.0 \pm 0.23,4.8 \pm$ 0.11 , and $4.9 \pm 0.10$ at baseline and $5.8 \pm 0.29,5.6 \pm$ 0.11 , and $5.7 \pm 0.14$ before the operation. After lung volume reduction surgery static respiratory system compliance decreased in all groups, but it did so more in group 3, the high resection volume group $(P=.000$ by analysis of variance, Figs 2 through 4 ). After the operation the mean compliances at $60 \mathrm{~mL}$ above FRC for groups 1, 2, and 3 were, respectively, $5.7 \pm 0.23,4.9$ \pm 0.12 , and $4.2 \pm 0.17$ (Table I).

Forced expiratory flow. Forced expiratory air flows were assessed at $33 \%$ of expiration $\left(\mathrm{FEF}_{33 \%}\right)$ with 20 $\mathrm{cm} \mathrm{H}_{2} \mathrm{O}$ body box pressure as previously described. ${ }^{1}$ The change in $\mathrm{FEF}_{33 \%}$ increased with greater than $3 \mathrm{~g}$ resection by an average of $16.5 \pm 25.3 \mathrm{~mL}$ (Fig 5). In contrast, the change in $\mathrm{FEF}_{33 \%}$ decreased by $22.4 \pm 8.3$ $\mathrm{mL}$ and $13.5 \pm 11.1 \mathrm{~mL}$ in groups 1 and 2 , respectively.

Diffusing capacity. The mean DLCO values ( \pm SEM) for groups 1,2 , and 3 were, respectively, $0.61 \pm 0.03$, $0.63 \pm 0.03$, and $0.67 \pm 0.04$ at baseline and $0.59 \pm 0.04$, $0.62 \pm 0.03$, and $0.63 \pm 0.03$ before the operation. The effects of lung volume reduction surgery on DLCO are 


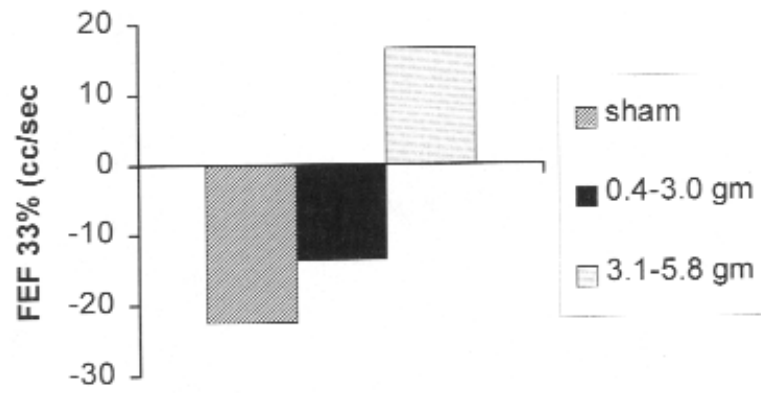

Resection Group

Fig 5. Graph shows change in forced expiratory flow with lung volume reduction surgery. Ordinate represents change in $\mathrm{FEF}_{33 \%}$ with lung volume reduction surgery. Abscissa represents treatment group. Analysis of variance, $P=.378$. Group 1 (sham), $\mathrm{n}=9$; group 2 (0.4-3.0 g), $\mathrm{n}=31$; group 3, (3.1-5.8 $g), \mathrm{n}=22$.

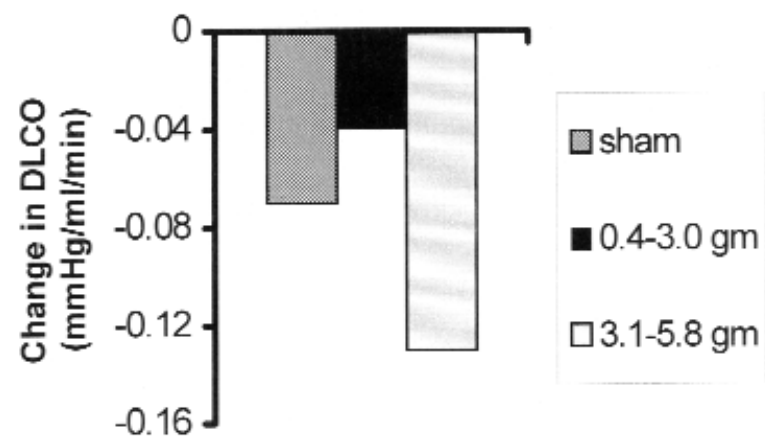

Fig 6. Graph shows change in DLCO with lung volume reduction surgery. Ordinate represents DLCO with lung volume reduction surgery. Abscissa represents treatment group. Analysis of variance, $P=.189$. Group 1 ( sham), $\mathrm{n}=9$; group 2 (0.4-3.0 g), $\mathrm{n}=31$; group 3, $(3.1-5.8 \mathrm{~g}), \mathrm{n}=22$.

shown in Figs 6 and 7 as the change in Deco from preoperative to postoperative values $(P=.189$ by analysis of variance). Although diffusing capacity deteriorated in all treatment groups after the operation, it declined most in the high resection volume group and least in the low resection volume group. The sham operation group had an intermediate decline in diffusing capacity. Our experience with this technique with the first 14 rabbits demonstrated a similar pattern of change in DLCO with lung volume reduction surgery. ${ }^{5}$ After the operation the mean DLCO value ( \pm SEM) for groups 1,2 , and 3 were, respectively, $0.52 \pm 0.03,0.57 \pm 0.03$, and $0.51 \pm 0.03$.

Histologic examination. Histologic examination confirmed the presence of mild to moderate diffuse emphysema in each animal at necropsy. The pattern of

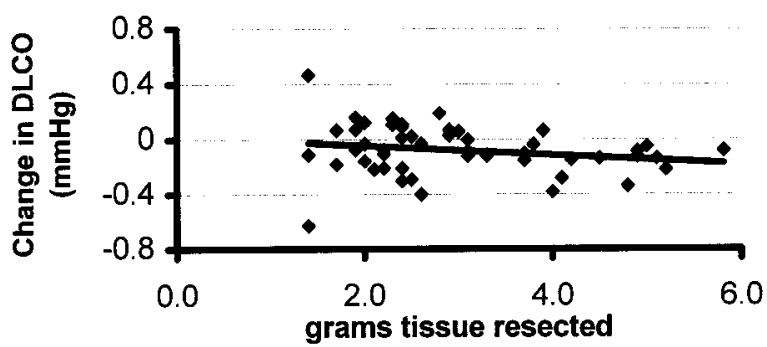

Fig 7. Graph shows change in DLCO as continuous function of amount of tissue resected with lung volume reduction surgery; $r=0.215$. $P=.133$. Total animals tested, $\mathrm{N}=67$.

Table I. Compliance with emphysema and lung volume reduction surgery

\begin{tabular}{lccc}
\hline & Baseline & Preoperative & $\begin{array}{c}\text { Postoperative } \\
(1 \mathrm{wk})\end{array}$ \\
\hline Sham operation & $5.0 \pm 0.23$ & $5.8 \pm 0.29$ & $5.7 \pm 0.23$ \\
Lung resection $\leq 3 \mathrm{~g}$ & $4.8 \pm 0.11$ & $5.6 \pm 0.11$ & $4.9 \pm 0.12$ \\
Lung resection $>3 \mathrm{~g}$ & $4.9 \pm 0.10$ & $5.7 \pm 0.14$ & $4.2 \pm 0.17$ \\
\hline
\end{tabular}

Values are mean compliance in millimeters per centimeter of water \pm SEM at $60 \mathrm{~mL}$ above FRC for 3 treatment groups at baseline, before the operation, and after the operation.

emphysema was centrilobular, patchy, and variable among individual rabbits.

\section{Discussion}

Lung volume reduction surgery is a rapidly evolving, dynamic area of research. This procedure has been proposed as potential palliative treatment for end-stage emphysema and as an alternative to lung transplantation for selected patients with end-stage emphysema. ${ }^{6,7}$ Many questions remain regarding patient selection criteria and optimization of clinical outcomes. It is essential that we understand both the physiologic mechanisms responsible for physiologic gain and the limiting factors for lung volume reduction surgery.

Loss of pulmonary elasticity is central to the pathophysiology of expiratory flow obstruction in emphysema. ${ }^{8}$ Clinically, emphysema is characterized by pulmonary and thoracic hyperexpansion caused by a loss of elastic recoil in the pulmonary parenchyma. Increased static compliance and decreased expiratory flows have been shown to occur with the development of emphysema in this elastase-induced animal model of pulmonary emphysema. ${ }^{1,9}$ In this study static respiratory system compliance increased with the development of emphysema in all rabbit groups. Compliance decreased toward baseline value with lung volume 
reduction surgery in proportion to the amount of lung volume resected (Figs 2 through 4). These data suggest that clinical improvement in elastic recoil may be proportional to extent of tissue volume resection.

Lung volume reduction surgery probably improves respiratory system compliance by increasing elastic recoil within the lung parenchyma. ${ }^{3,10}$ Removal of redundant pulmonary parenchyma improves recoil properties of the remaining parenchyma. Expiratory driving pressures increase while chest hyperexpansion is reduced, and respiratory mechanics return to a more physiologically usual state. Our findings suggest that greater resection of lung tissue yields greater benefit in elastic recoil. Patients with severe chest hyperexpansion may benefit from more extensive lung volume resection.

With lung volume reduction surgery, expiratory flow showed the greatest improvement in animals receiving large volume resection. Expiratory flow decreased in animals receiving low-volume resection. Expiratory flow has been correlated with airway resistance. ${ }^{1}$ Removal of emphysematous lung tissue may improve radial traction of remaining lung tissue to improve conductance of the airways.

It may appear counterintuitive that resection of pulmonary parenchyma would improve the gas exchange properties of the remaining pulmonary tissue in a disease characterized by destruction of the pulmonary parenchyma. Clinical studies have reported variable outcomes in diffusing capacity after lung volume reduction surgery, ranging from minimal improvement to $200 \%$ improvement with respect to preoperative values. $3,4,10,11$

An earlier report with this animal model demonstrated that DLCo improved slightly at resection volumes smaller than $3 \mathrm{~g}$ and then subsequently deteriorated to subpreoperative levels with higher resection volumes. ${ }^{5}$ The results of this investigation demonstrated a trend toward deterioration in diffusing capacity with lung volume reduction surgery in all treatment groups, with contrasting improvements in spirometry and compliance. Although the greatest decline in diffusing capacity was seen after resection of volumes larger than $3 \mathrm{~g}$, lung compliance and respiratory flows continued to improve with larger resections. It is likely that greater resection of pulmonary parenchyma reduces the ability of the lungs to transport gases. Gas diffusing capacity is governed by the quantity of functioning pulmonary capillaries, alveolar wall surface area and thickness, and ventilation-perfusion matching in extreme disease states. Resection of functioning capillaries and alveoli along with emphysematous tissue is probably responsible for the reduction in DLCO seen in our model. It is interesting that we saw less reduction in DLCO in the group receiving low-volume lung volume reduction surgery than in the rabbits undergoing sham operation. Improvements in ventilation-perfusion mismatch are the probable explanation for improvements in DLCO that have been reported in some cases. In this study it is possible that low-volume lung volume reduction surgery palliated some of the ventilation-perfusion mismatch and partially offset decreases in capillary bed and alveolar wall surface. If this is true, lung volume reduction surgery may provide greater palliation to patients with more severe ventilation-perfusion mismatch. A model of more severe emphysema may be needed to definitively clarify these issues.

The findings of this study suggest that resection of pulmonary parenchyma for mild to moderate emphysema impairs gas diffusing capacity and that this impairment limits the practical extent of lung resection. Whereas compliance shows improvements at larger resection volumes, diffusing capacity shows diminishing returns with increasing resection volumes. This raises concerns that patients who have reduced pulmonary vascular capacity and pulmonary hypertension may not tolerate extensive lung volume resection.

There are a number of limitations to this study. Histologic studies of this animal model confirm the presence of mild to moderate diffuse emphysema. Measurement of FRC with this animal model confirms an increase of approximately $30 \% .{ }^{1}$ However, increases approaching $250 \%$ may be seen in patients with severe chronic emphysema. Additionally, pulmonary hypertension and pulmonary vascular disease manifestations of chronic emphysema may require a longer time to develop fully than the 4 weeks of this study. The degree of physiologic changes may be milder in this model than seen clinically. The response to surgical treatment in milder disease may be different from the response in more severe disease states. Alternatively, the results of this study could also be interpreted to suggest that lung volume reduction surgery may afford clinical improvement to patients with less severe emphysema than that for which it is currently being recommended.

Pulmonary function measurements in this study were performed on anesthetized, paralyzed rabbits in a resting state. Cardiopulmonary physiology with exertion is different than with rest. The greater physiologic demands of exertion may allow resection of less tissue. Most patients with severe emphysema suffer dyspnea with exertion and not at rest. Diffusing capacity and pulmonary artery pressures may be highly sensitive to physical exertion.

Future studies should focus on identifying other 
physiologic variables that may decline with greater lung resection with observed deterioration in diffusing capacity. Because portions of the pulmonary capillary bed are resected with lung volume reduction surgery, a rise in pulmonary artery pressure may parallel declines in diffusing capacity. Pulmonary artery pressure measurements may provide useful intraoperative guidance in optimizing resection volume.

Clinical results have been variable with lung volume reduction surgery. The mechanisms of clinical improvement and limitations with lung volume reduction surgery have not been well described. This study suggests that optimal resection volumes with lung volume reduction surgery exist but may require a surgical approach individually tailored to the clinical physiologic presentation once a clearer understanding of the complex variables governing response to lung volume reduction surgery has been attained. Compliance and expiratory flow show maximal benefit with large lung resection volumes. In contrast, diffusing capacity showed less decline with lower lung resection volumes. Depending on the clinical presentation, some patients may benefit from larger lung resection volumes and other patients may benefit from more conservative lung resection volumes. Emphysema is a heterogeneous disease with a wide spectrum of presentation. Optimal surgical outcomes will result from thoughtful evaluation in the application of therapy.

\section{REFERENCES}

1. Huh J, Brenner M, Chen J, Yoong B, Gassel A, Kafie F, et al. Changes in pulmonary physiology alter lung volume reduction surgery in a rabbit model of emphysema. $\mathbf{J}$ Thorac Cardiovasc Surg 1998:115:328-35.

2. Brenner M, Yoong B, Budd M, Kafie F, Waite T, Mukai D, et al. The effect of lung volume reduction surgery on static compliance and maximal flows in a rabbit model of emphysema. Chest 1996:110(4 suppl):177S.

3. Sciurba FC, Rogers RM, Keenan RJ, Slivka WA, Gorcsan J, Ferson PF, et al. Improvement in pulmonary function and elastic recoil after lung-reduction surgery for diffuse emphysema. N Engl J Med 1996;334:1095-9.

4. O'Donnell DE, Webb KA, Bertley JC, Chau LK, Conlan AA. Mechanisms of relief of exertional breathlessness following unilateral bullectomy and lung volume reduction surgery in emphysema. Chest 1996;110:18-27.

5. Chen JC, Brenner M, Huh J, Yoong B, Gassel A, Kafie F, et al. Effect of lung volume reduction surgery on pulmonary diffusion capacity in a rabbit model of emphysema. J Surg Res 1998; 78:155-60.

6. Bavaria JE, Pochettino A, Kotloff RM, Rosengard BR, Wahl PM, Roberts JR, et al. Effect of volume reduction on lung transplant timing and selection for chronic obstructive pulmonary disease. $\mathrm{J}$ Thorac Cardiovasc Surg 1998;115:9-18.

7. McKenna RJ Jr, Brenner M, Fischel RJ, Singh N, Yoong B, Gelb
$\mathrm{AF}$, et al. Patient selection criteria for lung volume reduction surgery. J Thorac Cardiovasc Surg 1997;114:957-64.

8. Brantigan O, Mueller E, Kress MB. A surgical approach to pulmonary emphysema. Am Rev Respir Dis 1959;80:194-202.

9. Raub JA, Mercer RR, Miller FJ, Graham JA, O’Neil JJ. Dose response of elastase-induced emphysema in hamsters. Am Rev Respir Dis 1982;125:432-5.

10. Gelb AF, Brenner M, McKenna RJ Jr, Zamel N, Fischel R, Epstein JD. Lung function 12 months following emphysema resection. Chest 1996;110:1407-15.

11. Hazelrigg S, Boley T, Henkle J, Lawyer C, Johnstone D, Naunheim K, et al. Thoracoscopic laser bullectomy: a prospective study with three-month results. J Thorac Cardiovasc Surg $1996 ; 112: 319-26$

\section{Discussion}

Dr Joel D. Cooper (St Louis, Mo). I am interested in your animal model. We have been extremely frustrated during the last year trying to produce emphysema in dogs with a method that in the literature was said to yield emphysema, namely, inhalation of papain. We followed the published recipe, and we have obstructive lung disease but do not have emphysema. The papain model appears to produce a small-airway disease. You clearly produced a nice model of emphysema. What is the pattern of emphysema that you get with your model? In the histologic section you showed very nice alveolar destruction. I have 2 questions.

First, do you think that I could do the same thing in dogs with repeated elastase? Certainly the papain model has not worked. Second, in terms of clinical implication it clearly depends on the homogeneity or the heterogeneity of the model. In the clinical volume reduction situation, of course, one hopes to be removing volume without removing diffusing capacity, as it were, because there is no blood flow to the portion of the lung that is removed. Is your model relevant in that way; namely, do you produce more upper lobe disease than lower lobe disease or do you have a homogeneous pattern?

Dr Chen. With respect to the pattern of emphysema, this is a heterogeneous model. We did initial experiments, as reported in the Journal, ${ }^{1}$ illustrating that our pattern of emphysema was that of predominantly upper lobe. That is, with the technique we used the elastase appears to be selectively localized to the upper lobe region. This is a central lobar emphysema model, as graded by various histologic sectioning through different parts of the lung.

With respect to your question about papain in dogs, I am aware of some other groups that are trying to do this. We have not experimented with papain in rabbits. As to whether a dog model would be better than a rabbit model, I would only be speculating. The reason that we chose to work with rabbits was that the duration of the experiments was such that we were actually housing these rabbits for 6 weeks, and it may be that in fact we will need to house them even longer to develop a severe model of emphysema as opposed to a moderate model. As one can imagine, the costs of these experiments are not trivial.

Dr Larry R. Kaiser (Philadelphia, Pa). Comment a little 
bit more on your model. What is the natural history of the model? Do these animals die of emphysema? I mean, do they ultimately go ahead and die if you follow them up long enough? Also comment, if you will, on multiple inhalations of elastase versus the single inhalation of elastase with respect to the severity of the emphysema that is produced.

Dr Chen. In terms of the natural history, we have no data. Again, these animals were operated on after 4 weeks and at 1 week after the operation we killed them, so I cannot tell you about the natural history. This is an interesting question, though, and something that we can certainly look at.

In terms of multiple inductions versus single inductions, we are actually trying this. We unfortunately do not have enough data yet to give you any definitive conclusions. Perhaps next year we will present these data. In terms of multiple inductions, however, early results at least suggest that more severe emphysema is induced according to histologic profile. With respect to pulmonary function, there appears to be some increase in absolute lung volumes - that is, total lung capacity and residual volume-but I am not sure that this is going to turn out to be significant.

Dr David J. Sugarbaker (Boston, Mass). Could you comment on what might be a deficiency in the model? In human beings, of course, the respiratory embarrassment that ultimately results from chronic emphysema results in some chronic and rather static changes in chest wall mechanics and diaphragmatic activity. Could you comment on how this might affect your model, in the sense that you really have a 4-week effect and then you are really looking at some physiologic parameters?

Dr Chen. I am glad that you asked. The rabbit model is somewhat different from emphysema in human beings in that the rabbit chest wall - that is, the musculoskeletal component of it-is quite flexible, so that in fact we have done experiments to try to quantify the amount of elasticity of the chest wall and determine how that contributes into the elastic recoil of our calculations. So this will be somewhat different than that in a human individual.

The other important difference is that the rabbit is essentially a 4-legged animal, whereas human beings are not. Rabbits spend most of their lives prone, whereas human beings spend most of their lives upright. Certainly there are going to be some changes in pulmonary mechanics because of that. Nevertheless, we have found that our model produces predominantly upper lobe disease, which reflect the pattern seen in human beings.

With respect to other chronic changes, we are further evaluating pulmonary vascular changes in our rabbit model of emphysema. We hope to be able to correlate our laboratory findings with clinical findings in the near future. 